\title{
Análise textual discursiva na educação em ciências e matemática: Período de 2004-2020
}

\section{Marlúbia Corrêa de Paula ${ }^{1}$ e Gleny Terezinha Duro Guimarães ${ }^{2}$}

\author{
1 Universidade Estadual de Santa Cruz - UESC, Departamento de Ciências Exatas e \\ Tecnológicas - DCET, Ilhéus, Bahia, Brasil | mcpaula@uesc.br | https://orcid.org/0000-0002 \\ 3646-8700 \\ ${ }^{2}$ Pontifícia Universidade Católica do Rio Grande do Sul - PUCRS, Escola de Humanidades, \\ Porto Alegre, Rio Grande do Sul, Brasil | gleny@pucrs.br | http://orcid.org/0000-0001-8942- \\ 6750
}

Resumo. Introdução - Esta investigação pretende identificar o uso de Análise Textua Discursiva (ATD), buscando apresentar a sua trajetória a partir de material disponível no repositório online do Programa de Pós-Graduação em Educação em Ciências e Matemática (PPGEDUCEM), da Pontifícia Universidade Católica do Rio Grande do Sul (PUCRS), no município de Porto Alegre, estado do Rio Grande do Sul, Brasil, no período entre 2004 e 2020. Objetivos/Método - O objetivo é descrever o uso de análises textuais, com especial atenção à Análise Textual Discursiva (2004-2020), em suas etapas delimitadas como unitarização, categorização e metatexto. Trata-se de uma investigação qualitativa, que apresenta os dados coletados por meio da técnica de Mapeamento, com a utilização predominantemente de Mapas de Reconhecimento e Mapas de Identificação. Resultados/Conclusões - A presente pesquisa possibilitou o levantamento de 353 trabalhos disponíveis no repositório do Programa de Pós-Graduação e a identificação de 192 publicações com o uso desta metodologia de análise de dados textuais, além de reconhecer que a própria metodologia vai sendo delineada enquanto se constrói. Como contribuições, oportuniza o reconhecimento do trabalho desenvolvido neste programa de nível stricto sensu para o enriquecimento das metodologias utilizadas em análises textuais. Assim, sendo coaduno ao tratamento científico necessário às pesquisas realizadas no meio acadêmico a partir de diversos interesses educacionais.

Palavras-chave: Metatexto; Análise Textual Discursiva; Mapeamento.

Discursive Textual Analysis in Science and Mathematics Education: 2004-2020 Period

Abstract. Introduction. This investigation intends to identify the use of Discursive Textual Analysis (ATD), seeking to present its trajectory from material available in the online repository of Graduate Program in Science and Mathematics Education (PPGEDUCEM) at the Pontifical Catholic University of Rio Grande do Sul (PUCRS) - municipality of Porto Alegre State of Rio Grande do Sul, Brazil - in the period between 2004 and 2020. Objectives/Method. The objective is to describe the use of textual analysis with special attention to Discursive Textual Analysis in its stages named unitarization, categorization, and metatext. It is a qualitative investigation, which presents the data collected through the Mapping technique, with the predominantly use of Recognition Maps and Identification Maps. Results/Conclusions. This research enabled the survey of 353 works available in the repository of the Graduate Program and the identification of 192 publications using textual data analysis methodology, besides recognizing the methodology itself is being outlined while building. As contributions, it allows the recognition of work developed in this stricto sensu level program to enrich the methodologies used in textual analysis. Thus, being consistent with the scientific treatment necessary for research carried out in the academic environment based on different educational interests.

Keywords: Metatext; Discursive Textual Analysis; Mapping.

\section{Introdução}

Através da identificação do uso de Análise Textual Discursiva (ATD) busca-se apresentar o seu percurso, a partir do que se encontra disponível no repositório online do Programa de Pós-Graduação em Educação em Ciências e Matemática (PPGEDUCEM), da Pontifícia Universidade Católica do Rio Grande do Sul (PUCRS), situado no município/capital de Porto Alegre, no estado do Rio Grande do Sul, Brasil, no período entre 2004 e 2020. 
Com isso foi identificado um total de 353 trabalhos (333 dissertações e 20 teses), e 247 desse total fez uso de um tipo de análise textual, sendo que 180 dissertações e 12 teses fizeram uso de ATD, 48 dissertações sobre Análise de Conteúdo (AC); 5 dissertações e 2 teses sobre Análise de Discurso (AD) e no restante das teses e dissertações, foram utilizadas outras metodologias de análises de dados. Convém notar que enquanto a primeira defesa do referido programa de mestrado ocorreu no ano de 2005, em relação ao programa de doutorado isto data de 2016.

Em relação a este artigo, é necessário esclarecer que o foco dos tópicos não está em apresentar a constituição da metodologia ATD ou de seus pressupostos filosóficos, de modo a dissecá-la, mas objetiva descrever as metodologias adotadas nesse PPG, por meio da realização de um Mapeamento Teórico, e sua representação enquanto referenciais utilizados ao longo de quase duas décadas. Também não foram objeto de apresentação comparações entre AC, AD ou mesmo ATD.

Nesse sentido, a utilização da técnica de Mapeamento Teórico não será referida além de mencionados os mapas que a constituem e a escolha realizada para a recolha e a exposição de dados, os quais com quantidade e qualidade suficientes para demonstrarem a realização presente no objetivo deste artigo, ou seja, descrever produções quanto à metodologia de análise textual utilizada. Tal ação de descrever se cumpriu após encaminhamentos de de identificações e reconhecimentos. No que se refere à ATD, é oportuno destacar a forma como era denominada, ano a ano, até que se tornasse a ATD, atualmente, presente em publicações.

Destarte, a própria delimitação do período de recolha de dados se deve à condução da história da ATD desenvolvida no PPG. Ao mesmo tempo, a forma de descrição de suas etapas - do unitarizar até a escrita do metatexto - também vai sendo comunicada ao longo dos anos em publicações de dissertações. Por esse motivo, o objetivo deste artigo requereu o uso de um verbo de ação - descrever - que possibilitasse uma recolha ampla do que foi, aos poucos, sendo apresentado.

Segundo Richardson (2011, p. 62-63), "o objetivo geral define, de modo geral, o que se pretende alcançar com a realização da pesquisa". Para descrever a presença da ATD no PPGEDUCEM, foi necessário identificar as publicações desde o início do programa. Após, se pode contabilizar desde a variação do uso de metodologias textuais até os últimos anos em que a ATD, com referência em Moraes e Galiazzi (2007), passou a predominar. Para essa apresentação, utilizaram-se Mapas de Reconhecimento e Identificação, dependendo do modo como ocorreu o uso das análises textuais ao longo do período estudado. Dessa forma, quando o uso se tornou predominante sobre a ATD, foram utilizados os Mapas de Reconhecimento; quando o uso de análises foi variado, os Mapas de Indentificação.

Assim, para os períodos de 2004 a 2006; 2007 a 2008 e 2009 a 2010 foram utilizados, respectivamente, os Mapas de Identificação I, II e III. Para os períodos de 2011 a 2012; 2013 a 2016 e de 2017 a 2020 foram utilizados os Mapas de Reconhecimento IV, V,VI e VII. Cada Mapa apresentado neste artigo representa um período de até quatro anos, ao mesmo tempo em que se procura equilibrar a apresentação para manter a clareza da identificação, trazendo, em cada Mapa de Indentificação (I, II e III), um mínimo de 11 e um máximo de 26 trabalhos. A utilização desta técnica de apresentação dos dados coletados "[...] é um forte constituinte não somente para reconhecimento ou análise de dados, mas especialmente por proporcionar um vasto domínio do conhecimento existente na área investigada" (Biembengut, 2008, p. 90). Os mapas teóricos constituem-se dos seguintes momentos: Identificação dos trabalhos de interesse; Organização dos trabalhos identificados; Reconhecimento e Algumas Considerações (fechamento da análise realizada). Por opção, dadas as possibilidades de apresentação, neste artigo, utilizam-se para o fechamento das descrições, o Mapa de Análise I - Síntese a partir das identificações (I,II e III) e reconhecimentos (IV,V,VI e VII) realizados. 
A relevância de um levantamento sobre as publicações deste programa se deve ao fato de ter sido o professor Dr. Roque Moraes, in memoriam, o criador, por essa razão a referência inicial da metodologia de análise de dados qualitativos - ATD - e, ainda, por ter este autor, ao longo de sua docência, sido o idealizador deste programa stricto sensu' ${ }^{1}$. Passado o primeiro ano, portanto, em 2003, o mestrado passou de profissional a acadêmico. Nessa época, se estabeleceu a referência, hoje tida como a maior, para o uso da ATD. Tal referência está marcada desde a publicação do artigo "Uma tempestade de luz: a compreensão possibilitada pela análise textual discursiva" (Moraes, 2003, p.191211). Esse artigo está no primeiro capítulo da obra de Moraes e Galiazzi (2007), que, como se pode notar no Mapa de Identificação I, apresentado no tópico 1.2 deste artigo, esta referência tornou-se a de maior uso dentre as defesas realizadas até o ano de 2008 (Mapas de Identificação I, II). No sentido de autoria, da obra e de estudos voltados ao uso de ATD, a professora Dra. Maria do Carmo Galiazzi, orientanda do professor Dr. Roque Moraes, mantém pesquisas e aulas coadunas a esse propósito. Dado esse enlace da metodologia de ATD para com o PPGEDUCEM, a busca corresponde, inicialmente, ao ano de 2005, quando ocorreram registros de primeira defesa de dissertação; por sua vez, limita-se a busca no máximo ao ano de 2020, no intuito de atender a maior atualização possível para o levantamento que sustenta este artigo.

O critério utilizado para a seleção dos trabalhos foi a presença de análises textuais, e, com isso foram identificadas as seguintes referências: ATD ou Análise de Conteúdo (AC) Moraes (1987; 1994; 1998; 1999; 2002; 2003; 2005 e 2006); ATD - Moraes e Galiazzi (2006; 2007; 2011; 2012; 2013; 2014; 2016). AC - Bardin (1977; 2002; 2004 e 2009); Análise de Discurso - Foucault (1979); Pêcheux (1983 e 2000) e Orlandi (1999 e 2015).

Para obter esses dados, quando o resumo não apresentou a descrição do tipo de análise utilizada ou do autor a que se refere, fez-se a leitura do capítulo da metodologia destas publicações (teses e dissertações), procurando por palavras-chave subsidiadas pelos nomes dos autores: Moraes; Moraes e Galiazzi.

Como resultados da consulta, quanto ao acesso, identificou-se um total de 353 trabalhos, com link de acesso para os textos na íntegra, sendo 320 oriundos do curso de mestrado (2004-2020) e o restante do curso de doutorado (2016-2020). Tal explicitação constitui parte fundamental deste artigo, pois, de acordo com Gil (2012, p.50), se compreende que "o elemento mais importante para a identificação de um delineamento é o procedimento adotado para a coleta de dados".

Conforme Minayo (2011, p.15), "o endeusamento das técnicas produz um formalismo árido ou respostas estereotipadas. Seu desprezo, ao contrário, leva ao empirismo sempre ilusório em suas conclusões, ou a especulações abstratas e estéreis". Tendo em vista o objetivo do presente artigo, pretende-se identificar o que emerge das publicações do PPGEDUCEM sobre o uso de análises textuais, com ênfase voltada à observação sobre as metodologias que fizeram uso de ATD. Nesse sentido, não se pretende identificar dados para confirmar ou dar explicações, mas acompanhar o que advém da emergência dessas contribuições. Para tal efeito, este artigo tem na sua estrutura os seguintes tópicos: Introdução; Pesquisadores na Pesquisa Qualitativa; Percursos que se mostram a partir do Uso de Metodologias de Análises Textuais no PPGEDUCEM; e Considerações Finais.

\footnotetext{
${ }^{1}$ Após o "parecer favorável da Câmara de Pesquisa e Pós-Graduação, de 27 de abril de 2001, e da Capes, em 17 de dezembro, do mesmo ano, foi oferecido o curso de Mestrado Profissional em Educação em Ciências e Matemática1" (PUCRS, 2020, s.p [on-line]).
} 


\section{Pesquisadores na Pesquisa Qualitativa}

Assim como os participantes ocupam um lugar essencial nos estudos educacionais e científicos, sabe-se que a pesquisa, independentemente de seu cunho (qualitativa; quantitativa), tem apresentado avanços em termos de descrições metodológicas graças ao empenho de profissionais que, em suas áreas de colaboração, realizam aprofundamentos.

$\mathrm{Na}$ pesquisa qualitativa, o pesquisador é também um instrumento vivo de pesquisa. Segundo Minayo (2011, p.14), "[...] a criatividade do pesquisador (sua experiência, sua capacidade pessoal e sua sensibilidade)" é elemento metodológico.

Dessa forma, um exemplo de referências sobre metodologias está sobre a pesquisadora emérita da Fundação Oswaldo Cruz, socióloga e professora Dra. Maria Cecília de Souza Minayo ${ }^{2}$, cuja obra - "Pesquisa social: teoria, método e criatividade" - tem servido de norteador para aqueles que buscam estabelecer encaminhamentos de metodologia.

Outro exemplo parte do professor Dr. Antônio Carlos Gil, autor de "Métodos e técnicas de pesquisa social", obra que tem sido utilizada também em metodologias de análises, tanto qualitativas como quantitativas, e que contabilizam, até o momento, mais de 75.000 citações no google acadêmico.

Ainda, no sentido de reportar-se à história da pesquisa qualitativa, Gatti e André (2011) apresentam Robert Stake, pioneiro no uso de abordagens qualitativas em educação, que no ano de 1983 esteve no Brasil. Nesse mérito, Mendonça e Farias (2020, p.1) assim descrevem: "Robert Edward Stake é um dos pesquisadores americanos mais renomados por suas contribuições teóricas acerca de temas relacionados com a investigação científica, em particular as pesquisas qualitativas". Na sequência, as autoras citam os seguintes prêmios atribuídos ao professor Stake: 1998, Prêmio Lazarfeld, da American Evaluation Association; 1994, doutor honorário pela Universidade de Uppsala, na Suécia; 2009, pela Universidade Valladolid, na Espanha; 2007 homenageado pela American Educational Research Association.

Tendo realizado esse recorte, dá-se continuidade à apresentação de produções na Educação em Ciências e Matemática do PPGEDUCEM com uso de análises textuais empregadas em metodologias de pesquisas.

\section{Percursos que Utilizam Metodologias de Análises Textuais no PPGEDUCEM (2004-2020)}

A ATD vem recebendo aceite cada vez maior para uso em metodologias de análises de dados obtidos por contribuições textuais. A partir disso, se justifica a estrutura deste artigo traçando um itinerário de aplicabilidade metodológica. Com tal delineamento, se pode notar a forma como esse uso foi ganhando aceitação. Dado o extenso número de trabalhos, opta-se por não apresentar os títulos das dissertações e teses disponíveis no repositório ${ }^{3}$.

\footnotetext{
${ }^{2}$ Recebeu vários prêmios por seus méritos na área de saúde, dentre eles o de "Medalha de Mérito da Saúde "Oswaldo Cruz", conferido pelo Ministério da Saúde em 2009; o Prêmio de Direitos Humanos em 2014, conferido pela Presidência da República; e a Menção Honrosa de C\&T do CNPq. É bolsista 1A de produtividade do CNPq e Pesquisadora Emérita da FAPERJ e da FIOCRUZ - Texto obtido em Currículo Lattes. http://lattes.cnpq.br/4834272403601390

${ }^{3}$ http://tede2.pucrs.br/tede2/handle/tede/29
} 
Por esses motivos, também foram selecionados os Mapas de Identificação e de Reconhecimento. Assim, quando o período demanda variação de análises textuais, se faz a apresentação via Mapa de Identificação distribuídos nas delimitações de: (I) 2004 - 2006; (II) 2007 - 2008 e (III) 2009 - 2010.

Quando o período mantém uma forma de análise textual predominante, usa-se o de Mapa de Reconhecimento também delimitado em: (IV) 2004 - 2006; (V) 2011 - 2012; (VI) 2013 2016 e (VII) 2017 - 2020. Essa escolha se ancora nas diferentes formas de apresentação acolhidas nesses mapas, pois para identificar basta expor o dado coletado, estabelecendo dados pontuais, tais como: ano, tipo de análise textual realizada e autor da dissertação. Enquanto que para o reconhecimento os textos descritivos são adequados aos momentos em que se requer maior explicitações. Para a seleção do Mapa a ser utilizado é necessário ter atenção ao tipo de dado coletado, pois em alguns casos, é preciso fazer uso de mais de um tipo de Mapa ao mesmo tempo. Por isso, a delimitação inicial (2004-2006) suscitou o uso de Mapas de Identificação (I) e Reconhecimento (IV). Dessa forma, passa-se à apresentação inicial a partir dos Mapas de Identificação (I, II e III) e logo após, estão os Mapas de Reconhecimento (IV, V, VI e VII).

Tabela. 1. Mapa de Identificação I - 11 Dissertações identificadas no PPGEDUCEM (2004-2006)

\begin{tabular}{lll}
\hline Ano & \multicolumn{1}{c}{$\begin{array}{c}\text { Análise textual* } \\
\text { utilizada/referencial teórico }\end{array}$} & \multicolumn{1}{c}{$\begin{array}{c}\text { Autores que fizeram } \\
\text { uso de análises } \\
\text { textuais }\end{array}$} \\
\hline 2004 & - ATQ - Moraes $(2002,2003)$ & - \\
& ATQ - Moraes (2003b); AC - Bardin & Santos; \\
& Moreira; \\
2005 & ATQ - Moraes (2003) & Rodrigues; Stephani \\
& ATD - Não menciona referências & Zimmermann \\
& ATQ - Franco (2003) & Dias; \\
& ATD - Moraes (2003) & Schwarz (19o uso de ATD) \\
& ATQ - Ramos (1999) & Oliveira; \\
& ATQ - Moraes (2003; 2005) & Nicolini; \\
& AT - Moraes (1999; 2003) & Vettori; \\
& AT - Moraes (2003) & Nunes \\
\hline
\end{tabular}

* ATQ - Análise Textual Qualitativa; ATD - Análise Textual Discursiva; AT - Análise Textual

\subsection{Mapa de Reconhecimento IV - 11 Dissertações(2004-2006)}

No primeiro momento de apresentação dos mapas é necessário notar o percurso realizado na produção total do PPG, no período de 2004 - 2006, o qual levou a um total de 60 dissertações. Desse total, foram detalhadas as seguintes ocorrências:

- 2004 - de oito dissertações quatro fizeram uso de AC e quatro utilizam outras formas de análise de dados, portanto em nenhuma foi identificado o uso de ATD;

- 2005 - de 17 dissertações cinco utilizaram uma forma de análise textual (três ATQ; uma ATQ/AC; uma ATD - sem referência).

- 2006 - de 31 dissertações, seis utilizaram uma forma de análise textual, sendo três em ATQ, duas em AT, e para fechar este número, foi nesse ano que ocorreu a primeira dissertação com menção à ATD, com referência em Moraes e Galiazzi (2003) em Schwarz (2006).

Este detalhamento foi realizado para cada ano de levantamento, o que permitiu a escrita de considerações sobre a trajetória de usos da ATD na pesquisa qualitativa, a partir, desta busca, das produções do citado PPG. No entanto, não se faz possível a apresentação das descrições ano a ano, neste momento, dado a extensão gerada pela constituição de todos os mapas, que permitiram após a interpretação e seleção dos dados, a produção deste artigo. 
Para o atendimento ao objetivo proposto, fez-se a opção por mapas para pontuar a trajetória exclusiva do uso de metodologias que encaminharam ao que, atualmente, se denomina por ATD e, no mais, os detalhamentos podem ser consultados pelo leitor no site do PPG. Na sequência, são apresentados os Mapas de Identificação II e III.

Tabela 2. Mapa de Identificação II - 26 Dissertações identificadas no PPGEDUCEM (2007-2008)

\begin{tabular}{lll}
\hline Ano & \multicolumn{1}{c}{$\begin{array}{c}\text { Análise textual* } \\
\text { utilizada/referencial teórico }\end{array}$} & \multicolumn{1}{c}{$\begin{array}{c}\text { Autores que fizeram uso de } \\
\text { análises textuais }\end{array}$} \\
\hline & ATQD - Moraes (2003) & Osório; Machado; \\
ATQ - Moraes (2003) & Fries; \\
ATQ - Moraes (2005) & Moreira; Santos Júnior; \\
AT - Moraes (2005) & Fernandes; \\
ATD - Moraes (2003) & Perigolo; Menegotto; Wilges; Fávaro; \\
& ATD - Moraes e Galiazzi & $\begin{array}{l}\text { Kessler; Machado; Bins Neto; } \\
\text { Attenhofen; Silveira; Rocha; Lara; Freshi; } \\
\end{array}$ \\
& (2007) & Bacoon; Nörnberg; Pinho; Mello; \\
& ATD - Moraes (2003) & Timm; Etcheverria; Fagundes; Prestes
\end{tabular}

* ATQD - Análise Textual Qualitativa Discursiva; ATQ - Análise Textual Qualitativa; AT - Análise Textual; ATD - Análise Textual Discursiva

Como o interesse deste artigo recai sobre o uso da ATD, foi possível notar que os resultados delinearam também a identificação de diferentes formas de denominar a ATD, no período de 2003 até o ano de 2007. Nesse sentido, observa-se a seguinte linha percorrida por meio do esquema abaixo, constituído da seguinte lógica: sigla mencionada na metodologia acompanhada do ano em que ocorreu a dissertação.

$$
\text { ATQ (2005), ATQ, AT (2006); ATQD, ATQ, AT, ATD (2007), ATD (2008), }
$$

Fig. 1. Esquema I - 37 ocorrências da metodologia ATD (2005-2008)

Tabela. 3. Mapa de Identificação III - 24 Dissertações identificadas no PPGEDUCEM (2009 2010)

\begin{tabular}{|c|c|c|}
\hline Ano & Análise textual* utilizada/referencial teórico & $\begin{array}{c}\text { Autores que fizeram } \\
\text { uso de análises } \\
\text { textuais }\end{array}$ \\
\hline 2009 & $\begin{array}{l}\text { ATD - Moraes e Galiazzi (2003) } \\
\text { ATD - Moraes (2003); } \\
\text { ATD - Moraes e Galiazzi (2007); Moraes (2003); } \\
\text { ATD - Moraes e Galiazzi (2007); } \\
\text { ATD - Moraes }(2003,2006)\end{array}$ & $\begin{array}{l}\text { Marmitt; } \\
\text { Prestes; } \\
\text { Delazarri; } \\
\text { Souza; Boesing; } \\
\text { Grützmann; Garcez; } \\
\text { Santos; } \\
\text { Diedrich; } \\
\text { Bueno; }\end{array}$ \\
\hline 2010 & ATD - Moraes (2003) & $\begin{array}{l}\text { Petry; Martinelli; Fuck; } \\
\text { Lunkes; Fernandes; } \\
\text { Amaral; Soares; } \\
\text { Rebello; Arnoldo Junior; } \\
\text { Cunha; Brock; Gerhard; } \\
\text { Lucckesi; } \\
\text { Broi; }\end{array}$ \\
\hline
\end{tabular}

* ATD - Análise Textual Discursiva;

\subsection{Mapa de Reconhecimento V - 29 Dissertações (2011 - 2012)}

No ano de 2011, o uso de ATD está em 18 das 24 dissertações do programa. Em 2012, foram 18 dissertações defendidas, das quais, 11 utilizaram ATD, com o referencial adotado em Moraes e Galiazzi (2006; 2007). 


\subsection{Mapa de Reconhecimento VI - 53 Dissertações e 4 Teses (2013 - 2016)}

Nos anos situados no período de 2013 - 2016, do total de 75 dissertações defendidas no PPG 53 fizeram uso da ATD. As variações entre as referências utilizadas, nos anos 2010; 2011; 2012 e 2013, são apenas diferenciações da edição da obra de 2007. No ano de 2016, começaram a ocorrer as defesas de teses no PPGEDUCEM. Nesse ano, as 3 teses utilizaram a referência de Moraes e Galiazzi (2007) e uma homônima de 2005. Atentos às identificações, observou-se em uma dissertação a presença de uma forma de análise de dados qualitativos denominada de Interpretação Essencial Sintética, com autoria de Medeiros e Rocha Filho (2014).

\subsection{Mapa de Reconhecimento VII - 37 Dissertações e 10 Teses (2017 - 2020)}

No período de 2017 a 2020, foram defendidas 60 dissertações e 13 teses no PPG. Desse total, no ano de 2017, foram defendidas 22 dissertações, das quais 7 utilizaram ATD e 6 teses das quais, 4 fizeram o mesmo uso de metodologia de análise. O maior uso de ATD está no ano de 2018 (16 dissertações e 5 teses). Em 2019, a tese defendida fez uso de ATD bem como 9 dissertações fizeram uso dessa metodologia de análise de dados textuais. Em 2020, foram 5 dissertações e uma tese que fizeram uso de ATD.

\subsection{Mapa de Análise I - uma Síntese a Partir das Identificações (I, II e III) e Reconhecimentos (IV,V,VI e VII)}

Após a leitura dos trabalhos coletados para este artigo, pode-se observar que a primeira orientação do professor Moraes com uso de ATD, com etapas delimitadas descritas por unitarização, categorização e metatexto, ocorreu na dissertação de autoria de Nörnberg (2008). Aproveitando o Esquema I, apresentado neste artigo, é possível constatar que o uso da própria nomenclatura da metodologia discursiva passou por fases de construção até chegar ao ano de 2008, quando começa a ter maior uso. O termo metatexto, enquanto etapa da ATD, parece ter sido consolidado após a obra de Moraes e Galiazzi (2007).

Após percorrer um período que remontou quase duas décadas de publicações no repositório de PPGEDUCEM, na PUCRS, é possível afirmar que a ATD foi sendo absorvida pelo PPG enquanto ainda era delineada. E isso se transfere para os procedimentos adotados nesta metodologia, pois a ATD é sempre passível de ser novamente realimentada, admitindo, assim, a sua recursividade. Recursividade, impregnação, imersão, entre outros, são termos muito frequentes em Moraes e Galiazzi (2007). O que se pode perceber é que não são apenas termos utilizados, pois, de fato, a própria historicidade da ATD remonta esses sentidos.

Nisso se reafirma a possibilidade transformadora e o desafio de vencer os esforços necessários às (des)construções textuais, até que os dados tenham sido suficientemente trabalhados e, por ora, não ofereçam outras possibilidades para a pesquisa - por isso é assumida uma impregnação do pesquisador ao realizar análise por meio desta metodologia.

Mas não se engane, pois tudo poderá sempre ser revisto, reescrito e analisado sob outro ponto de vista. Essa metodologia é criteriosa, pois tem uma sequência de etapas, mas não é fechada em termos de delimitar os conteúdos de cada etapa. É analítica, ao mesmo tempo em que é interpretativa. E, sem compreender suas constituintes, essa impregnação não se dá de modo adequado, tão pouco teria sido possível traçar a trajetória desta metodologia sem antes a ter experimentado em diversos modos e objetivos de pesquisa. 
Por isso, a imersão sobre os pressupostos da própria ATD não surge do manuseio sobre publicações, mas sim dos estudos que já vêm sendo realizados sobre esta metodologia, os quais têm propiciado compreender como se dá por meio desse uso a formação de argumentos que emergem e são captados pelo metatexto.

Assim, o objetivo deste artigo, centrado em "descrever o uso de análises textuais, com especial atenção à Análise Textual Discursiva (2004 - 2020), em suas etapas delimitadas como unitarização, categorização e metatexto", foi realizado com a preocupação de apresentar os usos, ano a ano, e, ao mesmo tempo, chamar a atenção para o atual delineamento destas etapas. No entanto, neste artigo, foi possível apenas delinear os aspectos históricos desta trajetória, marcando, assim, o crescimento de tal uso ao longo de quase duas décadas e situando esse crescimento, por ora, a um único PPG.

Nesse interesse, o artigo foi constituído dentro do marco teórico da pesquisa qualitativa, mas sem se ater a descrever a condução teórica da própria ATD, pelos motivos já apresentados. Desse modo, é uma limitação deste artigo e, ao mesmo tempo, constitui uma possibilidade de continuidade de publicação para a contribuição de escrita de trabalhos, no que se refere aos tópicos de metodologias de pesquisas qualitativas que se inserem no uso de análises textuais com interesses em outros encaminhamentos. Por ora, basta descrever o que se mostra hoje, a partir do que tem sido publicado ao longo dos anos, no referido PPG, sobre suas escolhas metodológicas.

\section{Considerações Finais}

Por certo, a PUCRS não é a única instituição, no Brasil, a utilizar referências voltadas ao uso de ATD. Porém, dada a presença de Roque Moraes, também como docente e orientador em programas de pós-graduação, acredita-se que, dessa imersão, os procedimentos enunciados se mantêm ativos e têm sido disseminados por aqueles que um dia foram seus orientandos e hoje são reconhecidos pesquisadores na área educacional. A obra que predominou como referência neste artigo - Moraes e Galiazzi (2007) - tem, na presença da professora Dra. Maria do Carmo Galiazzi, sua continuidade com notória dedicação a esses estudos.

Por observar o crescimento do uso da ATD, foi possível descrever um histórico sobre essa presença e perceber as variações em suas denominações anteriores. Tal justificativa ainda se acentua tendo em vista que nem sempre a pesquisa qualitativa foi, no Brasil, ou numa acepção mais restrita, na área de educação, um recurso de uso comum. $\mathrm{Na}$ condução do levantamento realizado, de 2005 até 2020, se pode verificar no repositório online da PUCRS, um total de 192 publicações de diferentes interesses de pesquisa que se utilizaram unicamente de análises por meio de ATD para descrever situações de ensino e de aprendizagens, entre outras.

Dessa maneira, o objetivo de identificar, durante a realização do levantamento sobre as teses e dissertações do PPGEDUCEM, a ocorrência dos modos de descrever a metodologia de análise realizada, se mostrou pertinente, pois, de fato, o próprio termo metatexto passou a ser utilizado nos trabalhos logo após a publicação da obra homônima da ATD, no ano de 2007. Também se pode reconhecer o percurso sobre a forma como essas publicações tratavam a própria denominação da análise, passando por Análise Textual Qualitativa - Análise Textual Qualitativa e Análise textual - Análise textual Qualitativa Discursiva, Análise Textual Qualitativa, Análise Textual e, por fim, ATD.

Outra questão que se fez presente foi o uso insistente da prerrogativa de que nos objetivos sejam acolhidos os sentidos de "o que se mostra", pois isso é uma exigência do significado da própria perspectiva fenomenológica na qual se insere a ATD enquanto metodologia. Sendo assim, tendo cumprido as pretensões objetivas, conclui-se este artigo com a intenção de oferecer ao leitor um trabalho que se inscreva numa perspectiva que contribua para a história da análise qualitativa. 


\section{Referências}

Bardin, L. (1977). Análise de Conteúdo. Lisboa: Edições 70.

Bardin, L. (2002). Análise de Conteúdo. Lisboa: Edições 70.

Bardin, L. (2004). Análise de Conteúdo. Lisboa: Edições 70.

Bardin, L. (2009). Análise de Conteúdo. Lisboa: Edições 70.

Bardin, L. (2016). Análise de Conteúdo. São Paulo: Edições 70.

Biembengut, M.S. (2008). Mapeamento na Pesquisa Educacional. Rio de Janeiro: Ciência Moderna.

Foucault, M. (1987). A Arqueologia do Saber. (3 $3^{\underline{a}}$ ed). Rio de Janeiro: Forense.

Franco, M.L. (2003). Análise do Conteúdo. Brasília: Plano.

Gatti, B.A., \& André, M. (2011). A Relevância dos Métodos de Pesquisa Qualitativa em Educação no Brasil. In W. Weller, \& N. Pfaff (Orgs.). Metodologias da Pesquisa Qualitativa em Educação: Teoria e Prática. (2ª ed). (pp. 29-38). Petrópolis: Vozes.

Gil, A.C. (2012). Métodos e Técnicas de Pesquisa Social: Gêneros Textuais do Argumentar e do Expor.(6 ed.). São Paulo: Atlas.

Mendonça, L.de O.S., \& Farias, I.M.S. (2020). Pesquisa Qualitativa: Estudando como as Coisas Funcionam. Educação: Teoria e Prática, 30(63), 1-7.

Minayo, M.C.S., Gomes, R., \& Deslandes, S.F. (Orgs.) (2011). Pesquisa Social: Teoria, Método e Criatividade. (30 $\mathrm{a}$ ed.) Petrópolis: Vozes.

Moraes, R. (2003). Uma Tempestade de Luz: A Compreensão Possibilitada pela Análise Textual Discursiva. Ciência \& Educação, 9(2), 191-211.

Moraes, R. (1991). A Educação de Professores de Ciências: Uma Investigação da Trajetória de Profissionalização de Bons Professores. (Tese de Doutorado em Educação, Universidade Federal do Rio Grande do Sul, Brasil) < https://lume.ufrgs.br/handle/10183/150313>

Moraes, R. (1999). Análise de conteúdo. Revista Educação, 22(37), 7-31.

Moraes, R. (2002a). Educar pela Pesquisa: Exercício de Aprender a Aprender. In R. Moraes, R., V.M.R. Lima, V. M. (Orgs.). Pesquisa em Sala de Aula: Tendências para Educação em Novos Tempos (pp. 127-142). Porto Alegre: EDIPUCRS.

Moraes, R. (2005). Mergulhos Discursivos: Análise Textual Qualitativa Entendida como Processo Integrado de Aprender, Comunicar e Interferir em Discursos. In M.C. Galiazzi, \& J.V. Freitas. (Orgs.). Metodologias Emergentes de Pesquisa em Educação Ambiental. ljuí: Unijuí.

Moraes, R. \& Galiazzi, M.C. (2013). Análise Textual Discursiva. (2ª ed. rev.) ljuí: Unijuí.

Moraes, R., \& Galiazzi, M.C. (2011). Análise Textual Discursiva. (2ª ed.). ljuí: Unijuí.

Moraes, R. (1998). Análise de Conteúdo. Educação, 21(34), 7-37.

Moraes, R. (2002). Análise de Conteúdo. Educação, 21, 5-31.

Moraes, R. (1994). Análise de Conteúdo: Possibilidades e Limites. In M.E.A. Engres (Org.). Paradigmas e Metodologias de Pesquisa em Educação. Porto Alegre: EDIPUCRS.

Moraes, R. (1987). Análises Qualitativas: Análise de Conteúdo? Análise de Discurso? Rio de Janeiro: Paz e Terra.

Moraes, R. (2006). Da Noite ao Dia: Tomada de Consciência de Pressupostos Assumidos dentro das Pesquisas Sociais.

Moraes, R. (2002). Mergulhos Discursivos: Análise Textual Qualitativa Entendida como Processo Integrado de Aprender, Comunicar e Interferir em Discursos. Porto Alegre: PUCRS.

Moraes, R. 2003) Uma Tempestade de Luz: A Compreensão Possibilitada pela Análise Textual Discursiva. Ciência e Educação, Bauru, v. 9, n. 2, p.191-210, 2003. 
Vol. 7 | Investigação Qualitativa em Educação: Avanços e Desafios

Moraes, R., \& Galiazzi, M.C. (2006). Análise Textual Discursiva: Processo Reconstrutivo de Múltiplas Faces. Ciência e Educação, 12(1), 117-128.

Moraes, R., \& Galiazzi, M.C. (2014). Análise Textual Discursiva. (2ª ed. rev.) ljuí: Unijuí.

Moraes, R. (2002). Teoria e pesquisa. Porto Alegre.

Moraes, R., \& Galiazzi, M.C. (2007). Análise Textual Discursiva. ljuí: Unijuí.

Nörnberg, I.F. (2008). Ciência em Revista: A Construção de Conhecimentos Científicos através da Utilização de Histórias em Quadrinhos. (Dissertação de Mestrado em Ciências e Matemática, Pontifícia Universidade Católica do Rio Grande do Sul, Brasil) < http://tede2.pucrs.br/tede2/handle/tede/3323>

Orlandi, E.P. (2015). Análise de Discurso. (12ª ed.). Campinas, SP: Pontes.

Orlandi, E.P. (1999). Análise de Discurso: Princípios e Procedimentos. Campinas, SP: Pontes.

Pêcheux, M. (1983). A Análise Automática do Discurso. In F. GADET, \& T. HAK (Orgs.). Por uma Análise Automática do Discurso: Uma Introdução à Obra de Michael Pêcheux. (pp. 61-105) Campinas, SP: UNICAMP

Pêcheux, M. (2000). Estrutura ou Acontecimento. (6ª ed.) Campinas; SP: Pontes.

Richardson, R.J. et al. (2011). Pesquisa Social: Métodos e Técnicas. (3ª ed.) São Paulo: Atlas. 